\title{
LEEDUS: A MICRoMACHINING PROCESS FOR DIE-SCALE PATTERN TRANSFER IN CERAMICS WITH HIGH RESOLUTION AND THROUGHPUT
}

\author{
Tao $\mathrm{Li}^{1}$ and Yogesh B. Gianchandani \\ Engineering Research Center for Wireless Integrated Microsystems \\ University of Michigan, Ann Arbor, Michigan
}

\begin{abstract}
While ceramics are important materials for electronic and microsystem packaging, they are difficult to pattern lithographically. LEEDUS, a fabrication process combining lithography, electroplating, batch mode micro electro-discharge machining $(\mu \mathrm{EDM})$ and batch mode micro ultrasonic machining ( $\mu \mathrm{USM}$ ), is presented in this paper. This technology provides diescale pattern transfer capability from lithographic masks onto ceramics, glass or other brittle materials. This is done by using the photomask to create an electroplating mold, then using the electroplated pattern as an electrode to $\mu \mathrm{EDM}$ a hard metal tool, which is finally used in the $\mu$ USM of the ceramic substrate. A minimum feature size of $25 \mu \mathrm{m}$ has been demonstrated on the glass-mica $\left(\right.$ Macor $^{\mathrm{TM}}$ ) ceramic plate with a $4.5 \mathrm{~mm} \times 4.5 \mathrm{~mm}$ die size and $34 \mu \mathrm{m}$ cutting depth using a stainless steel microtool. The machining rate in the demonstration was about $18 \mu \mathrm{m} / \mathrm{min}$, and the tool wear ratio for the microtool was $6 \%$. The average surface roughness was $\mathrm{Ra} 0.55 \mu \mathrm{m}$. Other process characteristics are also discussed.
\end{abstract}

\section{INTRODUCTION}

Ceramics play an increasingly important role in electronic and MEMS packaging areas because of their unique electrical, chemical, mechanical, and physical properties. Typically, they are hard, electrically and thermally insulating with high melting temperatures and high chemical stability. However, they are also brittle, with low toughness and ductility. In addition to conventional semiconductor devices and IC high-performance packaging, ceramics also find attractive applications for microsystem packaging such as hermetic packages made entirely of ceramic or combination of ceramic and metals, in which cases, holes, grooves or complex patterns are often required on the ceramic substrates.

Although superb for packaging applications, the properties of ceramics also make them difficult to process lithographically. Consequently, in conventional IC packaging industry ceramics are often processed by dry pressing or tape casting from a powder form [1]. These additive processes usually face the problems of volume shrinkage, high temperature steps, and varying material properties. Serial subtractive processes like laser drilling or diamond grinding, which are most commonly used for conventional precision machining of ceramics, are less attractive for complex patterns which can be best made when structures are defined by a mask. Reactive ion etching (RIE) is limited by a slow etch rate and varying gas requirements for different ceramics [2]. Powder blasting provides good machining rates, but is limited by V-shaped sidewalls and blast lag [3] [4]. Phosphoric acid or other wet chemical etchings for ceramics suffer from quite limited etching rate and achievable minimum feature size due to lateral undercutting [5]. Thus, a bulk process with pattern-transfer capability is greatly desired.
This paper presents LEEDUS, a fabrication process which utilizes micro ultrasonic machining ( $\mu$ USM) in batch mode to transfer a mask-defined die-scale pattern from a micro electrodischarge machined ( $\mu$ EDM'ed) microtool into a ceramic plate with high resolution and throughput.

Conventional ultrasonic machining (USM) has been widely accepted as an effective machining process for hard and brittle materials like ceramics, glass and silicon. Since these materials are brittle, it is easier to fracture them than to plastically deform them, and USM produces little or no damage or high-stress deformation at or below the surface. Moreover, it causes no thermal or chemical alterations in the sub-surface characteristics of the machined material, and can achieve precision surface finish of $\mathrm{Ra}$ $0.4 \sim 0.76 \mu \mathrm{m}[6]$. However, at the micro level, USM has been used only as a serial process with a rotating cutting tool, thereby limiting both throughput and structural shapes [7] [8]. The batch mode $\mu$ USM approach presented in this paper facilitates die-scale transfer of complex lithographic patterns and provides relatively high resolution - the best reported in the past is about $25 \mu \mathrm{m}$ - as well as high throughput, while retaining the favored characteristics of conventional USM.

\section{PROCESS DESCRIPTION}

The LEEDUS process flow is illustrated in Figure 1. A copper structure is electroplated into an SU-8 mold on a silicon substrate with lithography-defined negative pattern. Then the silicon die is used as an electrode to batch $\mu \mathrm{EDM}$ a stainless steel or $\mathrm{WC} / \mathrm{Co}$ microtool, transferring the corresponding positive die-

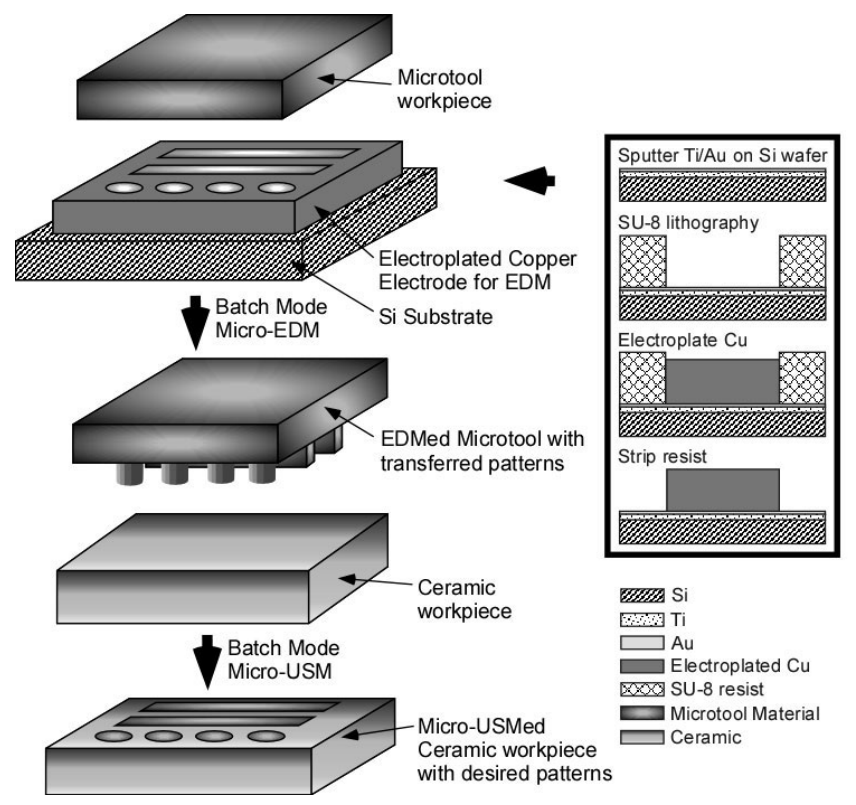

Fig. 1: Concept of LEEDUS: combining Lithography, Electroplating, batch mode micro Electro-Discharge machining, and batch mode UltraSonic machining.

\footnotetext{
${ }^{1}$ Corresponding author: 1301 Beal Ave., Ann Arbor, MI, 48109, USA; Tel: (734) 647-2040, Fax: (734) 763-9324.
} 


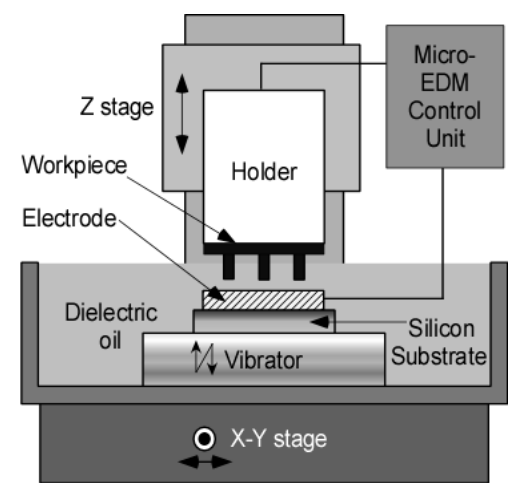

Fig. 2: $\mu$ EDM setup used for batch mode microtool fabrication.

scale pattern onto the microtool [9] [10]. The microtool is then mounted on an ultrasonic machining setup for batch mode $\mu$ USM of a ceramic workpiece, thus having the desired negative pattern transferred onto the ceramic workpiece.

Figure 2 shows a schematic diagram of the setup for $\mu \mathrm{EDM}$ based on the Panasonic $\mu$ EDM machine MG-ED72W. This setup has $\mathrm{X}-\mathrm{Y}-\mathrm{Z}$ stages with $0.1 \mu \mathrm{m}$-precision relative positioning of the microtool workpiece and copper electrode. The copper electrode is fixed on a vibrator which can vibrate in the feeding $(Z)$ direction of the microtool workpiece with a frequency of $100 \mathrm{~Hz}$ and adjustable amplitude. This vibration is necessary to avoid welding when a short circuit occurs between the electrode and the workpiece, as well as to facilitate removal of machining debris.

The schematic diagram for the batch mode $\mu$ USM setup is shown in Figure 3 . The $\mu$ EDM'ed microtool is firmly and carefully mounted by epoxy at the tip of the horn where the vibration energy generated by the ultrasonic transducer is maximized. An appropriate abrasive slurry which consists of water and fine abrasive powders is supplied between the tip of the microtool and a ceramic workpiece. The vibrating tip of the microtool is fed into the ceramic workpiece. The ultrasonic motion of the microtool imparts velocity to the abrasive particles on its downward stroke. These particles, in turn, are responsible for the erosion of the workpiece, thus creating the desired cavities in the shape of the microtool.

\section{EXPERIMENTAL DETAILS}

A $4.5 \mathrm{~mm} \times 4.5 \mathrm{~mm}$ silicon die with $50 \mu \mathrm{m}$ high electroplated copper structures was used as the electrode for batch mode $\mu \mathrm{EDM}$ with discharge voltage of $80 \mathrm{~V}$ and discharge control capacitance of $100 \mathrm{pF}$. Figure 4 shows SEM images of two of the demonstrative copper patterns, both of which have features with lateral

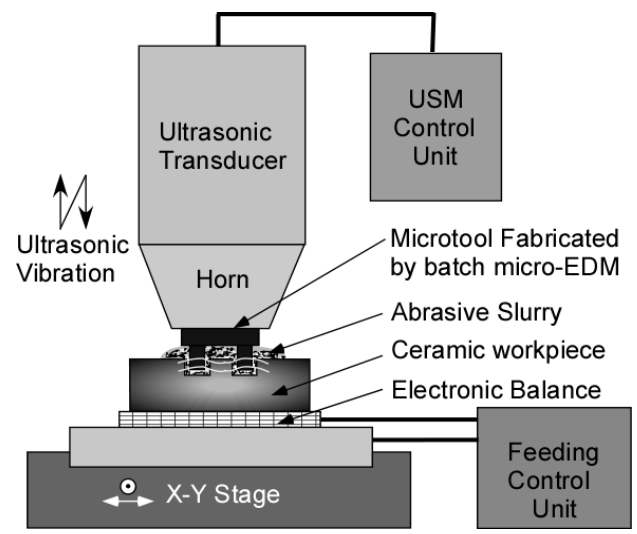

Fig. 3: $\mu$ USM setup used for batch mode pattern transfer to ceramic workpiece.

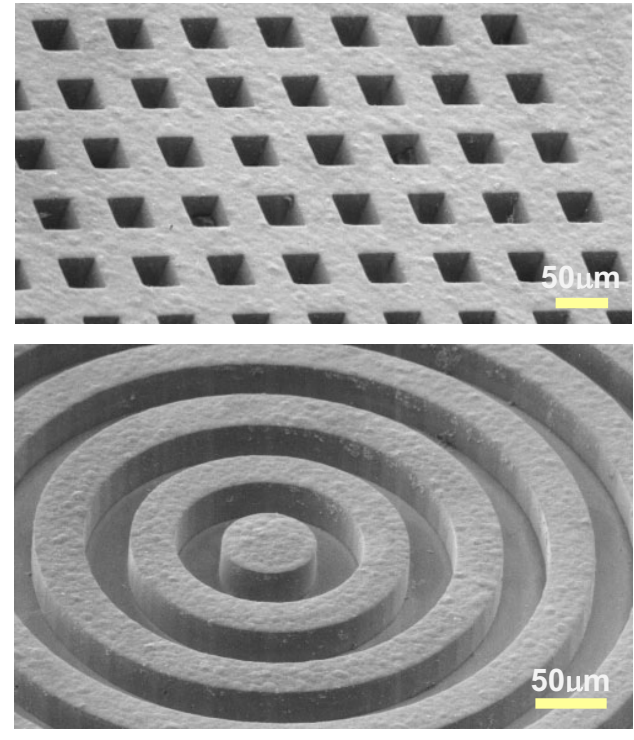

Fig. 4: SEM images of two of the patterns on the electroplated copper electrode die (both have $40 \mu \mathrm{m}$ feature size).

dimension of $40 \mu \mathrm{m}$. Figure 5 shows $\mu$ EDM'ed microtools made with stainless steel and $\mathrm{WC} / \mathrm{Co}$. The grainy nature of $\mathrm{WC} / \mathrm{Co}$ leads to a rougher finish. The $40 \mu \mathrm{m}$ features in the copper pattern are reduced to $24 \mu \mathrm{m}$ on the microtool due to the $\mu \mathrm{EDM}$ discharge gap which was measured as about $8 \mu \mathrm{m}$. This gap is generally determined by the discharge energy and is stable under fixed discharge conditions. The dimension of the electrode patterns should be designed while keeping this gap in mind.

These microtools were then used for batch mode $\mu$ USM on a
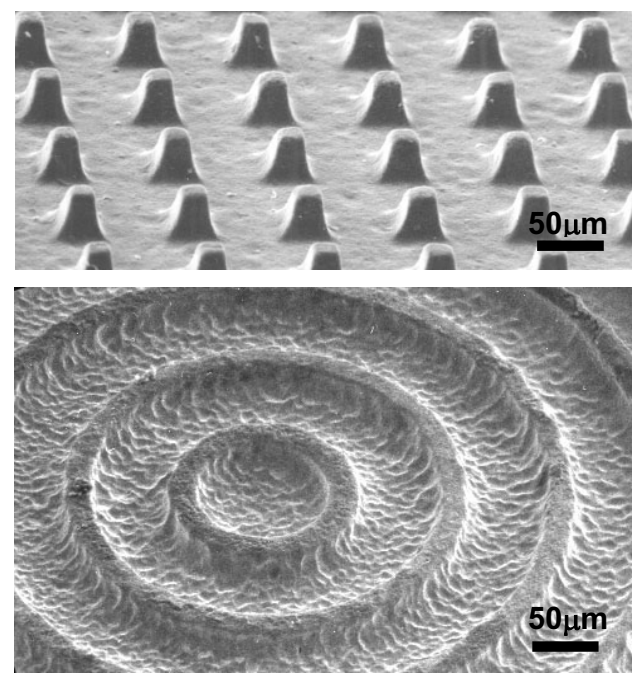

(b)

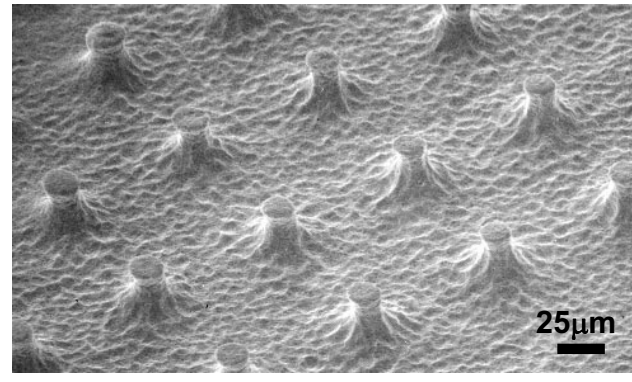

(c)

Fig. 5: SEM images of batch mode $\mu$ EDM'ed microtools: (a) stainless steel microtool pattern of $35 \mu \mathrm{m}$ height; (b) and (c) $\mathrm{WC} / \mathrm{Co}$ microtool pattern with poles array of $32 \mu \mathrm{m}$ height. 
Table I: Properties of the ultra-high temperature glass-mica $\left(\right.$ Macor $^{\mathrm{TM}}$ ) ceramic plate used in the demonstration (McMaster Carr 8489K231).

\begin{tabular}{|l|l|}
\hline Temperature Range & $-185^{\circ} \mathrm{C} \sim 800^{\circ} \mathrm{C}$ \\
\hline Flexural Strength & $94 \mathrm{MPa}$ \\
\hline Compressive Strength & $345 \mathrm{MPa}$ \\
\hline Dielectric Strength & $3.94 \times 10^{7} \mathrm{volt} / \mathrm{m}$ \\
\hline Thermal Conductivity & $1.46 \mathrm{~W} / \mathrm{m} \cdot \mathrm{K}$ \\
\hline Density & $2.5 \times 10^{3} \mathrm{Kg} / \mathrm{m}^{3}$ \\
\hline Others & Nonporous, opaque white \\
\hline
\end{tabular}

glass-mica (Macor ${ }^{\mathrm{TM}}$ ) ceramic plate whose properties are shown in Table I. The ultrasonic vibration utilized for the demonstration had a frequency of $20 \mathrm{KHz}$ and amplitude of $15 \mu \mathrm{m}$. The abrasive was WC powder with particle size of $0.5 \sim 1 \mu \mathrm{m}$. Results are shown in Figures 6 and 7. A minimum feature size of $25 \mu \mathrm{m}$ on the ceramic plate was achieved with a machining depth of $34 \mu \mathrm{m}$. The overall process performance achieved at this time is summarized in Table II.

The average machining rate observed in this demonstration was about $18 \mu \mathrm{m} / \mathrm{min}$, with $\sim 5 \mathrm{~mm}^{2}$ cutting surface area and $\sim 0.5 \mathrm{~N}$ machining load. For USM, the machining rate usually increases with any of the following: the brittle fracture hardness of the workpiece material, mean radius of abrasive grains, working load applied in the cutting zone, amplitude of vibration, and frequency of oscillation [11]. Figure 8 shows the change of machining rate with increasing amplitude of ultrasonic vibration. A linear relationship was assumed for the dashed trend line. Although larger amplitude results in faster machining speed, the surface
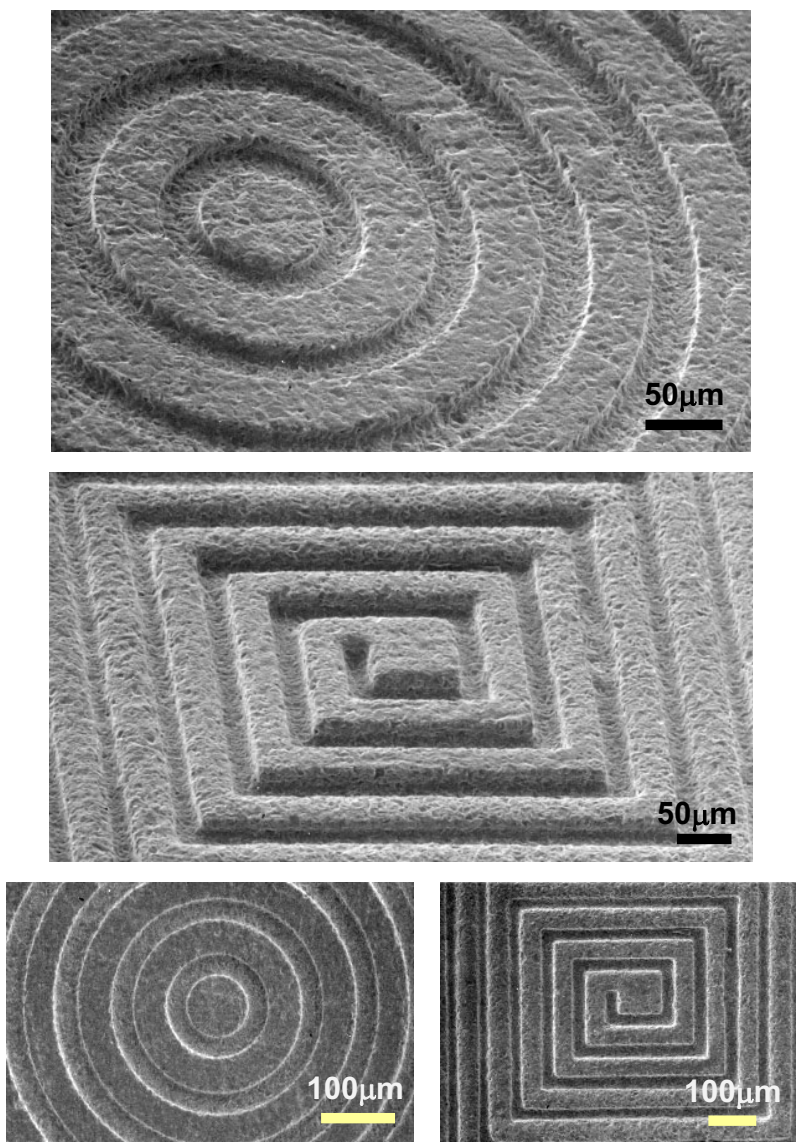

Fig. 6: SEM images of two of the patterns transferred onto ceramic surface in perspective view showing depth, and corresponding top-down view showing fidelity of the features.

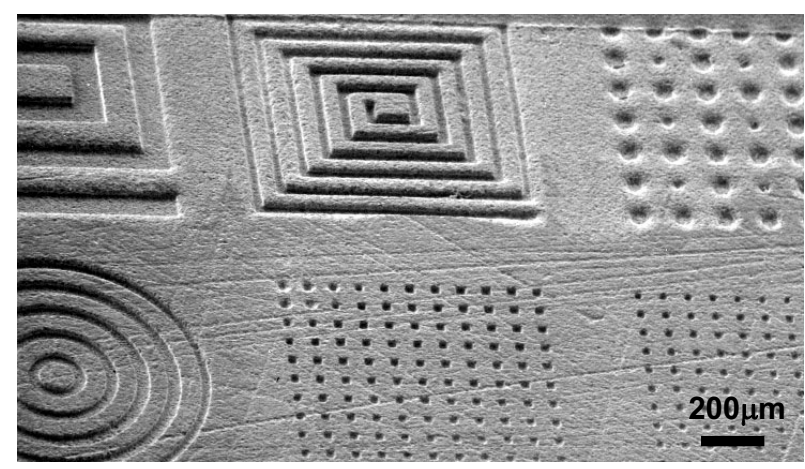

Fig. 7: SEM image of patterns on the ceramic surface transferred from the die-scale microtool.

Table II: Machining parameters for the batch mode $\mu$ USM of the Macor ceramic plate.

\begin{tabular}{|l|l|}
\hline Transducer frequency & $20 \mathrm{KHz}$ \\
\hline Vibration amplitude & $15 \mu \mathrm{m}$ \\
\hline Abrasive powders & $\mathrm{WC}(0.5 \sim 1 \mu \mathrm{m})$ \\
\hline Batch machining die area & $4.5 \mathrm{~mm} \times 4.5 \mathrm{~mm}$ \\
\hline Avg. machining rate & $18 \mu \mathrm{m} / \mathrm{min}$ \\
\hline Machining load & $\sim 0.5 \mathrm{~N}$ \\
\hline Minimum feature size & $25 \mu \mathrm{m}$ \\
\hline Cutting depth & $34 \mu \mathrm{m}$ \\
\hline Surface roughness (Ra) & $\begin{array}{l}\sim 0.55 \mu \mathrm{m}(0.4 \mu \mathrm{m} \text { for the } \\
\text { raw material) }\end{array}$ \\
\hline Tool wear ratio(height) & $<6 \%$ (Stainless steel) \\
\hline
\end{tabular}

finish becomes rougher and chips can occur.

Figure 9 (a) shows the copper electrode after $\mu \mathrm{EDM}$ of the stainless steel microtool. A tool wear ratio of $\sim 29 \%$ was measured, which corresponds to $\sim 10 \mu \mathrm{m}$ loss of copper tool height for making a $35 \mu \mathrm{m}$ high microtool. This tool wear can be simply compensated by increasing the SU-8 mold height to get a higher copper electrode, or can be reduced using parallel discharge mode $\mu$ EDM with partitioned die area as described in [10].

The wear ratio of $\mu$ USM microtools usually varies with different tool materials, or changes with machining parameters such as machining load, abrasive powder size, etc. In order to compare microtool materials, the WC/Co microtool was also tested for $\mu \mathrm{USM}$ under the same machining parameters. Figure 9 (b) and (c) show post-use stainless steel and $\mathrm{WC} / \mathrm{Co}$ microtools respectively. The stainless steel microtool wore less than $2 \mu \mathrm{m}$ for the $34 \mu \mathrm{m}$ cutting depth, giving a wear ratio of $<6 \%$, while the $\mathrm{WC} / \mathrm{Co}$ microtool showed a tool wear ratio of more than $25 \%$. This suggests stainless steel should be a better choice for this

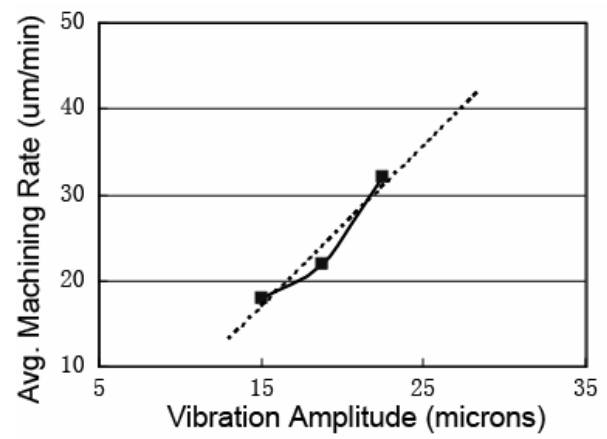

Fig. 8: Variation of machining rate as the amplitude of ultrasonic vibration is increased (Other machining parameters remain the same as in the demonstration). 


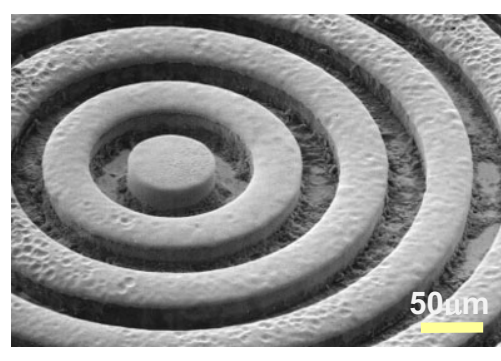

(a)
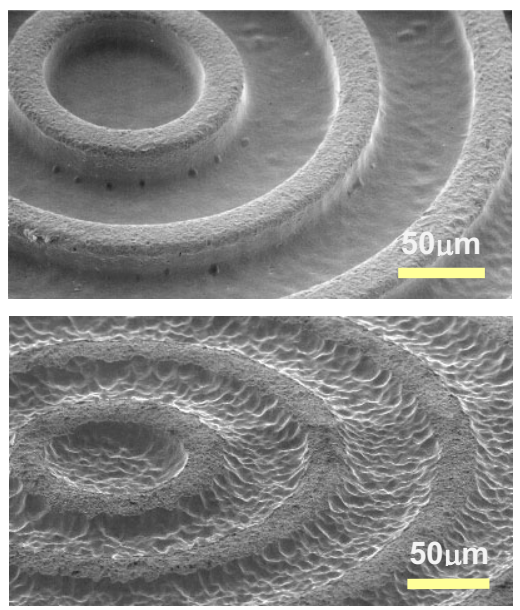

(b)

(c)

Fig. 9: Post-use SEM images of a: (a) copper electrode used after $\mu \mathrm{EDM}$ of the steel microtool, tool wear ratio $\sim 29 \%$; (b) stainless steel microtool, after $\mu \mathrm{USM}$ of the ceramic part, tool wear ratio $<6 \%$; (c) WC/Co microtool, after $\mu \mathrm{USM}$ of the ceramic part, tool wear ratio $>25 \%$.

application, opposing the usual preference for $\mathrm{WC} / \mathrm{Co}$. The reason for this divergence is still under investigation.

Figure 11 shows the hole sizes distribution for the $11 \times 11$ array of $30 \mu \mathrm{m}$ features in Figure 10. Average hole width is $29.4 \mu \mathrm{m}$. The standard deviation of hole sizes is less than $2 \mu \mathrm{m}$, providing acceptable size uniformity for many applications.

\section{CONCLUSIONS}

A new fabrication process which combines lithography, electroplating, batch mode $\mu \mathrm{EDM}$ and batch mode $\mu \mathrm{USM}$ has been developed to provide die-scale pattern transfer capability from lithographic mask onto ceramics, glass or other brittle materials with high throughput and resolution. A demonstrative die-scale pattern with $25 \mu \mathrm{m}$ minimum feature sizes and spacing was defined with a mask and transferred onto the workpiece by stainless steel and $\mathrm{WC} / \mathrm{Co}$ microtools with a machining speed of about $18 \mu \mathrm{m} / \mathrm{min}$. The experimental results are very promising for further improvements and will be pursued in future efforts.

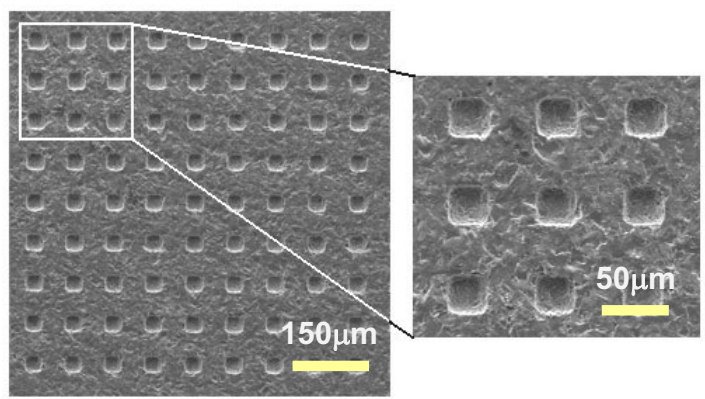

Fig. 10: SEM images of an array of $30 \mu \mathrm{m}$-width holes fabricated on the ceramic plate.

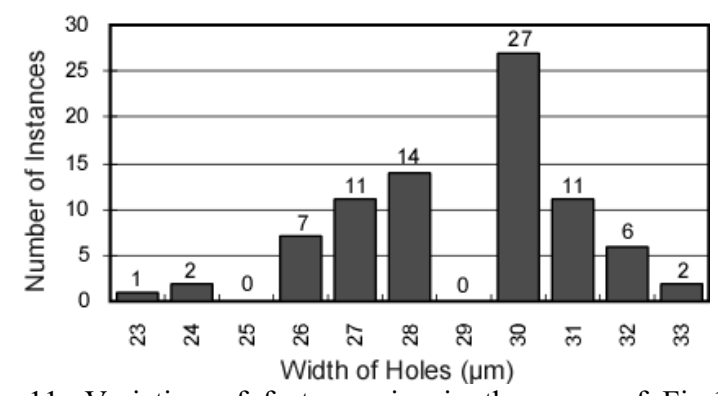

Fig. 11: Variation of features size in the array of Fig.10 Gaussian distribution of hole widths around the mean value. Mean hole width: $29.4 \mu \mathrm{m}$. Standard deviation: $1.9 \mu \mathrm{m}$.

\section{ACKNOWLEDGEMENT}

The authors are grateful to the Solid-State Electronics Laboratory (SSEL) colleagues at the University of Michigan, esp. Mr. K. Takahata, Mr. K. Udeshi and Dr. S. McNamara for their help with equipment. The authors also appreciate Prof. K. Najafi and Mr. J. Giachino at UM WIMS ERC for valuable discussions. This work was supported primarily by the Engineering Research Centers Program of the National Science Foundation under Award Number EEC-9986866. Travel support has been generously provided by the Transducers Research Foundation and by the DARPA MEMS and DARPA BioFlips programs.

\section{REFERENCES}

1. W. D. Brown, Advanced Electronic Packaging: with emphasis on multichip modules, IEEE Press, New York (1999).

2. S. Wang, X. Li, K. Wakabayashi, and M. Esashi, "Deep Reactive Ion Etching of Lead Zirconate Titanate Using Sulfur Hexafluoride Gas," Journal of the American Ceramic Society, v 82, n 5, pp. 1339-41 (May 1999).

3. H. Wensink, J. W. Berenschot, H. V. Jansen, and M. C. Elwenspoek, "High resolution powder blast micromachining," Proc. of the IEEE Micro Electro Mechanical Systems (MEMS), pp. 769-774 (2000).

4. M. Wakuda, Y. Yamauchi, and S. Kanzaki, "Material response to particle impact during abrasive jet machining of alumina ceramics," Journal of Materials Processing Technology, v 132, n 1-3, pp. 177-183 (Jan 10, 2003).

5. E. Makino, T. Shibata, and Y. Yamada, "Micromachining of fine ceramics by photolithography," Sensors and Actuators A (Physical), v 75, n 3, pp. 278-288 (Jun. 1999).

6. T. B. Thoe, D. K. Aspinwall, and M. L. H. Wise, "Review on ultrasonic machining," International Journal of Machine Tools \& Manufacture, v 38, n 4, pp. 239-255 (Apr. 1998).

7. X. Sun, T. Masuzawa, and M. Fujino, "Micro ultrasonic machining and its applications in MEMS," Sensors and Actuators A (Physical), v A57, $\mathrm{n} 2$ 2, pp. 159-64 (Nov. 1996).

8. H. Choi, S. Lee, and B. Lee, "Micro-hole machining using ultrasonic vibration," Key Engineering Materials, v 238-239, pp. 29-34 (2003)

9. K. Takahata, N. Shibaike, H. Guckel, "High-aspect-ratio WCCo microstructure produced by the combination of LIGA and micro-EDM," Microsystem Technologies, v6, n5, pp.175-8 (2000). 10. K. Takahata, and Y. B. Gianchandani, "Batch Mode MicroElectro-Discharge Machining," IEEE/ASME J. Micromechanical Systems, 11(2), pp. 102-110 (Apr. 2002).

11. M. Komaraiah, and P. N. Reddy, "A study on the influence of workpiece properties in ultrasonic machining," International Journal of Machine Tools \& Manufacture, v33, n3, pp. 495-505 (1993). 